\title{
BMJ Open Women's weight and disordered eating in a large Norwegian community sample: the Nord-Trøndelag Health Study (HUNT)
}

\author{
Trine Eik-Nes, ${ }^{1,2}$ Ulla Romild, ${ }^{3}$ Ismail Guzey, ${ }^{1}$ Turid Holmen, ${ }^{4}$ Nadia Micali, ${ }^{5}$ \\ Sigrid Bjørnelv ${ }^{1,2}$
}

To cite: Eik-Nes T, Romild U, Guzey I, et al. Women's weight and disordered eating in a large Norwegian community sample: the Nord-Trøndelag Health Study (HUNT). BMJ Open 2015;5: e008125. doi:10.1136/ bmjopen-2015-008125

- Prepublication history for this paper is available online. To view these files please visit the journal online (http://dx.doi.org/10.1136/ bmjopen-2015-008125).

Received 6 March 2015 Revised 30 June 2015 Accepted 30 July 2015

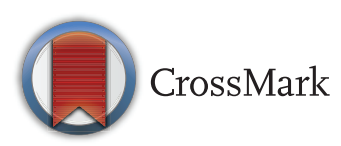

\footnotetext{
${ }^{1}$ Department of Neuroscience, Norwegian University of Science and Technology, Trondheim, Norway

${ }^{2}$ Department of Psychiatry, Levanger Hospital, Levanger, Norway

${ }^{3}$ Research Department, NordTrøndelag Hospital Trust, Levanger, Norway

${ }^{4}$ Norwegian University of Science and Technology, HUNT Research Center, Public Health and General Practice, Trondheim, Norway ${ }^{5} \mathrm{UCL}$ Institute of Child Health, London, UK
}

Correspondence to Dr Trine Eik-Nes; trine.t.eik-nes@ntnu.no

\section{ABSTRACT}

Objectives: An increasing part of the population is affected by disordered eating (DE) even though they do not meet the full eating disorder (ED) criteria. To improve treatment in the range of weight-related disorders, there is a need to improve our knowledge about DE and relevant correlates of weight problems such as underweight, overweight and obesity. However, studies investigating DE and weight problems in a wide range of ages in the general population have been lacking. This paper explores DE, weight problems, dieting and weight dissatisfaction among women in a general population sample.

Design: Cross-sectional study.

Setting: The third survey of the Nord-Trøndelag Health Study (HUNT3).

Participants: The population included 27252 women, aged 19-99 years, with information on DE outcomes and covariates.

Outcomes: DE was assessed with an 8-item version of the Eating Attitude Test and the Eating Disorder Scale-5. Body mass index (BMI) was objectively measured. Data on dieting and weight dissatisfaction were collected from self-reported questionnaires and analysed across weight categories. Crude and adjusted logistic and multinomial logistic regression models were used.

Results: High rates of overweight (38\%) and obesity (23\%) were found. DE was associated with weight problems. In women aged $<30$ years, $11.8 \%(95 \% \mathrm{Cl}$ 10.3 to 13.1$)$ reported $\mathrm{DE}$, and $12 \%(95 \% \mathrm{Cl} 11.5$ to 12.6) reported $D E$ in women aged $>30$ years. In those of younger ages (19-29 years), lower weight predicted $\mathrm{DE}$, while increasing weight predicted DE in older aged women (30-99 years). The majority of women were dissatisfied with their weight $(58.8 \%)$, and $54.1 \%$ of the women reported dieting. Neither BMI status nor age was associated with dieting or weight dissatisfaction.

Conclusions: A high prevalence of DE was observed, and findings suggest that weight problems and DE are not distinct from one another. Dieting was associated with women's weight dissatisfaction, rather than with actual weight. This requires further investigations about directionality of effects.

\section{Strengths and limitations of this study}

- This large general population study found a high prevalence $(12 \%)$ of disordered eating (DE), especially in women with weight problems.

- Dieting was associated with weight dissatisfaction.

- Neither intention to lose weight nor weight dissatisfaction were associated with body mass index or age.

- Prevention and treatment of DE and weight control should include assessments of body image.

- Estimation of prevalence of DE in this study is a methodological challenge due to the use of less well-established measures.

\section{BACKGROUND}

Parallel with the increasing social pressures to be thin, increases in obesity rates are worrying. ${ }^{1}$ Furthermore, the prevalence of disordered eating (DE) and eating disorders (EDs) seems to be increasing. ${ }^{2-8}$ Weight problems include both extremes, underweight and overweight/obesity, however, the burden of obesity is more pronounced in the Western world.

EDs such as anorexia nervosa, bulimia nervosa and binge EDs are present in only about $5-10 \%$ of the population, ${ }^{9}$ however, they constitute a significant public health problem due to their high burden on the healthcare sector and the associated high mortality. ${ }^{10}$ A larger part of the population is affected by DE or sub-threshold ED with prevalence rates of DE reported to be $15 \%$ or higher; these produce significant morbidity even though the participants do not meet the full ED criteria. ${ }^{11} 12$

Previous studies have found that EDs and obesity can be associated. ${ }^{13}{ }^{14}$ Additionally, there is considerable evidence showing weight concerns and dieting/unhealthy weight-control behaviours to be shared risk 
factors for both EDs and obesity. ${ }^{14}$ The inclination to identify oneself as overweight despite having a healthy body size has been of concern due to its association with increased risks for ED ${ }^{15}{ }^{16}$ Dieting (ie, intentions to lose weight) has been associated with both obesity and EDs, ${ }^{17} 18$ and prospective data suggest that dieting is not effective for weight loss. ${ }^{19}$

Owing to increasing prevalence of weight-related disorders and DE, researchers and clinicians have highlighted the need to initiate prevention programmes that target both. ${ }^{20}$ To improve prevention and treatment across weight-related disorders and DE, there is a need to improve our understanding of how these are related in community samples.

We sought to study weight problems, and a range of DE symptoms and behaviours in a population-based sample: The Nord-Trøndelag Health Study (HUNT). In addition, we also sought to examine factors related to DE such as dieting and weight dissatisfaction. Hence, the aims of the study were to: (1) estimate the prevalence of DE, (2) estimate the prevalence of weight dissatisfaction and dieting and (3) determine the associations between weight problems, DE, weight dissatisfaction and dieting behaviours in a large general population sample of adult women across a wide age range.

\section{METHODS}

\section{Study population}

The HUNT survey invites the total population, 13 years and above, in Nord-Trøndelag County, Norway. Three surveys have been conducted: HUNT1 (1984-1986), HUNT2 (1995-1997) and HUNT3 (2006-2008). ${ }^{21}$ The total county population aged 20 years or more was invited ( $\mathrm{N}=93860)$ and $52 \%$ participated. A total of 47293 women were invited and $58.7 \%$ participated.

The present study includes data from HUNT3 on 27252 adult women between ages 19 and 99 years. All participants completed questionnaires and underwent clinical examinations at temporarily located health examination sites staffed by certified fieldwork teams. The participants received a questionnaire including an assessment of DE when they attended the health examination sites, which were to be completed at home, and returned by mail in a prepaid envelope. About $80 \%$ of the participants returned the questionnaire.

Of the participants, $504(1.85 \%)$ were excluded because they were pregnant or because height or weight was not measured. Men were excluded ( $n=23049)$ from the study due to DE being more common in women and because we sought to investigate specific associations in women. However, it would have been very interesting to also study men (figure 1).

\section{Measures}

Disordered eating

For the young adults (19-30 years) in HUNT3, a shortened version of the Eating Attitude Test (which we here

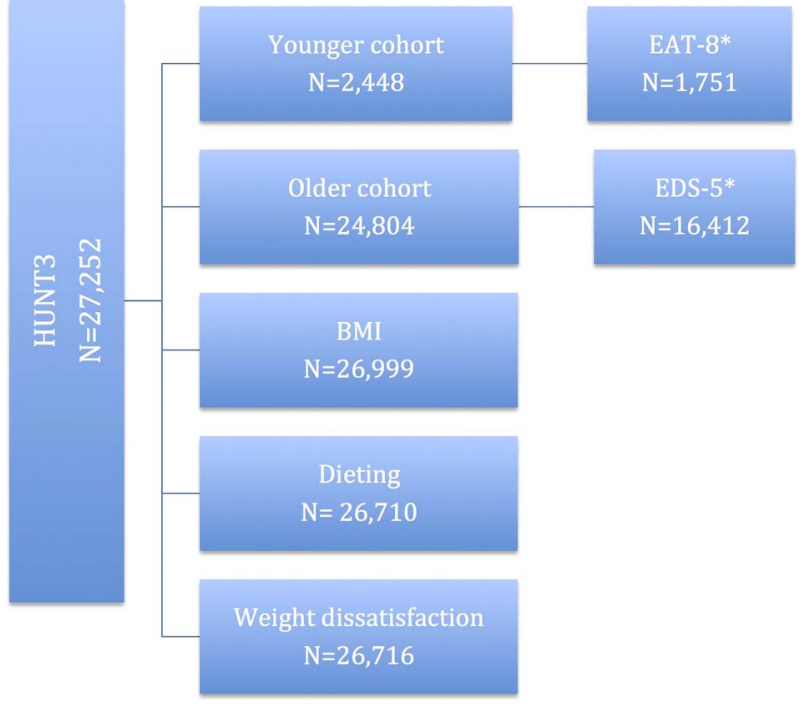

Figure 1 Illustration of the study population and variables measured (BMI, body mass index; EAT, Eating Attitude Test-8; EDS-5, Eating Disorder Scale-5; HUNT, Nord-Trøndelag Health Study).

refer to as the EAT- 8$)^{22}$ involving two factors, 'oral control' (EAT-A) and 'bulimia and food preoccupation' (EAT-B), was used to assess DE because of limited space in the questionnaire. Thus, the dieting factor included separately elsewhere in the questionnaire was removed, and the items used consisted only of the two factors 'oral control' (EAT-A) and 'bulimia and food preoccupation' (EAT-B). The EAT-8, EAT-A (anorexia subscale/oral control) explored attitudes with regard to the following items: (1) When I eat, I cut my food up into small pieces; (2) It takes me longer than it takes others to finish a meal; (3) Other people think I'm too thin and (4) I feel that others pressurise me to eat; while EAT-B (bulimia subscale/food preoccupation) explored the following: (1) When I first begin eating, it is difficult to stop; (2) I spend too much time thinking about food; (3) I feel that food controls my life; and (4) I vomit after I have eaten. A three-point Likert scale with the response options: never/seldom, often and always, was used and coded as 0,1 and 2, respectively. The original version of the EAT is a standardised self-report measurement of symptoms for detection of individuals at risk of developing ED. ${ }^{22} \mathrm{~A}$ 12-item version of the EAT was validated in a former Norwegian study, ${ }^{23}$ and the consistency in terms of sensitivity and specificity between EAT-7 and EAT-12 was later evaluated. ${ }^{24}$ In this study, we used the cut-off scores as outlined by Bjomelv et $a l^{24}$ with scores $\geq 3$ for EAT- 8 and EAT-A and $\geq 2$ for EAT-B as indicative of DE.

Controls were those who scored less than the aforementioned cut-offs on EAT-A, EAT-B or EAT-8, respectively. A cut-off $\geq 5$ on EAT-7 in the adolescent part (13-19 years) of the HUNT survey (Young HUNT) ${ }^{25}$ gave high specificity, however, the sensitivity was deemed too low. $^{24}$ The original EAT applied a six-point scale, while a 
four-point scale was used in this present study. The items had four alternative answers: 'never', 'seldom', 'often' and 'always'. In this present study, 'never' and 'seldom' were recoded to 0 , 'often' as 1 and 'always' as 2, which gave a maximum score of 8 for EAT-A and 8 for EAT-B in EAT-8. The internal consistency of EAT-8, EAT-A and EAT-B was, respectively, 0.595, 0.512 and 0.695, determined by Cronbach's $\alpha$.

The EAT questions were chosen for the young adults, as some of these represented a follow-up population of the adolescents 13-19 years of age who participated in HUNT2. A psychiatric expert advisory group insisted, however, on the use of the Eating Disturbance Scale $(\text { EDS-5 })^{26}$ for assessment of DE in ages $30-99$ years. The items assessed were (1) Have you ever felt guilty about eating? (2) Have you ever felt that it was necessary for you to use a strict diet or other eating rituals to control your eating? (3) Have you ever felt that you are too fat? (4) Have you ever eaten to comfort yourself because you were unhappy? (5) Are you satisfied with your eating habits?

Scores ranged from 0 (never, seldom) to 2 (sometimes, always) with higher scores reflecting greater DE. The EDS-5 had a high level of internal consistency in this study (Cronbach's $\alpha=0.835$ ). In this study, participants who scored above the 90 th centile (score $\geq 23$ ) were considered 'at-risk' of having an ED.

Owing to the limited use of EDS-5 in the general population, sum scores from the present study were compared with sum scores from a clinical sample of 60 women diagnosed with severe ED. Identification of these 60 participants was made based on ICD-10 diagnosis according to current diagnostic guidelines where 29 were diagnosed with Anorexia Nervosa (AN), 9 with atypical AN, 15 with Bulimia Nervosa (BN) and 5 with atypical BN. Mean sum scores from the present study, the clinical sample and the initial validation study of EDS-5 were $13.41 \quad(\mathrm{SD}=6.71), 24.08(\mathrm{SD}=4.24)$ and 10.98 $(\mathrm{SD}=7.72)$, respectively. The Eating Disorder Inventory (EDI-2) ${ }^{27}$ was collected from the clinical sample for comparison and the mean sum score of the EDI-2 in the clinical sample was $103.73(\mathrm{SD}=36.8)$. A sum score of $\geq 23$ was comparable to the mean sum score in the clinical sample and hence deemed satisfactory as indicative of $\mathrm{DE}$ in this population.

\section{Anthropometric measures}

Height and weight were measured with the participants wearing light clothes and no shoes. ${ }^{28}$ Height was measured to the nearest centimetre $(\mathrm{cm})$ and weight to the nearest half kilogram $(\mathrm{kg})$. Body mass index (BMI) was calculated as $\mathrm{kg} / \mathrm{m}^{2}$. Participants were classified in accordance with WHO classifications in the following categories: underweight as $\mathrm{BMI}<18.5 \mathrm{~kg} / \mathrm{m}^{2}$, normal weight as BMI $18.5-24.9 \mathrm{~kg} / \mathrm{m}^{2}$, overweight as BMI $25.0-$ $29.9 \mathrm{~kg} / \mathrm{m}^{2}$, obesity as $\geq 30 \mathrm{~kg} / \mathrm{m}^{2}$ and extreme obesity as $\mathrm{BMI} \geq 35 \mathrm{~kg} / \mathrm{m}^{2}$.

\section{Education}

Education was measured as the highest level of education achieved and dichotomised into lower education (primary school and secondary school) and higher education (1-3 years of higher education or $>4$ years of higher education).

\section{Weight dissatisfaction}

Weight dissatisfaction was assessed using the following question, 'Are you satisfied with your weight now?', and coded into a binary variable weight satisfaction ('yes') and weight dissatisfaction ('no, too heavy' and 'no, too light').

\section{Dieting}

Dieting was assessed with the following question, 'Have you been trying to diet in the last 10 years?', and categorised as a three-level categorical variable indicating non-dieters ('no'), occasional dieters ('yes, sometimes') and recurrent dieters ('yes, many times'). The 10-year dieting interval was chosen as the HUNT surveys were completed at 11-year intervals.

\section{Smoking}

Participants' smoking was categorised as a three-level categorical variable indicating 'non-smokers', 'occasional smokers' and 'daily smokers'.

\section{Statistical analyses}

The data were initially set up using IBM SPSS statistics V.21. Frequencies, percentiles, means and SDs were calculated for key variables. Logistic regressions were employed to calculate ORs and 95\% CIs for associations between DE and weight. Multinomial logistic regressions were employed to calculate ORs and 95\% CIs for the association between dieting and weight. In multivariate models, analyses were adjusted for covariates such as education, smoking and age, thought a priori to be potential confounders of the association between the exposure and outcomes of interest. All analyses were run with complete outcome and exposure data.

\section{Ethical approval}

Participation in the HUNT survey and the present study was voluntary and based on written informed consent. The Norwegian Data Inspectorate, The Regional Committee for Ethics in Medical Research in Central Norway (REC Central) and the Norwegian Directorate of Health, approved the HUNT surveys.

\section{RESULTS}

Sample characteristics are given in table 1. A total of 27252 women from ages 19 to 99 years took part in this study (mean age 53, SD 16.3). Mean BMI was $26.9 \mathrm{~kg} / \mathrm{m}^{2}$ (SD 4.9). Two-thirds (65.1\%) of participants had a lower level of education. 
Table 1 Sample characteristics

\begin{tabular}{|c|c|c|}
\hline & $\mathbf{N}$ & Per cent ${ }^{\star \star}$ \\
\hline \multicolumn{3}{|l|}{$\mathrm{BMI}, \mathrm{kg} / \mathrm{m}^{2}$} \\
\hline Underweight <18.5 & 242 & 0.9 \\
\hline Normal weight 18.5-24.9 & 10253 & 38.0 \\
\hline Overweight 25.0-29.9 & 10260 & 38.0 \\
\hline Obese $\geq 30$ & 4479 & 16.6 \\
\hline Extremely obese $\geq 35$ & 1765 & 6.5 \\
\hline \multicolumn{3}{|l|}{ Education } \\
\hline Lower & 16681 & 65.1 \\
\hline Higher & 8954 & 34.9 \\
\hline \multicolumn{3}{|l|}{ Smoking } \\
\hline Non-smokers & 21045 & 75.8 \\
\hline Occasional smokers & 1684 & 6.1 \\
\hline Daily smokers & 5027 & 18.1 \\
\hline \multicolumn{3}{|l|}{ Dieting } \\
\hline Non-dieters & 12257 & 45.9 \\
\hline Occasional dieters & 10854 & 40.6 \\
\hline Frequent dieters & 3599 & 13.5 \\
\hline \multicolumn{3}{|l|}{ Age, years } \\
\hline 19-29 & 2448 & 9.0 \\
\hline 30-39 & 3858 & 14.2 \\
\hline $40-49$ & 5322 & 19.9 \\
\hline $50-59$ & 5978 & 21.9 \\
\hline $60-69$ & 5103 & 18.7 \\
\hline $70+$ & 4443 & 16.3 \\
\hline
\end{tabular}

Of all women in the sample, $61.1 \%$ were either overweight or obese, $23.1 \%$ being in the obese range. There were 242 women $(0.9 \%)$ in the underweight category. However, 966 women $(3.5 \%)$ had a $\mathrm{BMI} \leq 20 \mathrm{~kg} / \mathrm{m}^{2}$. The largest group of underweight women was found in the age group 19-30 years. BMI increased with age, and obesity $\left(\mathrm{BMI} \geq 30 \mathrm{~kg} / \mathrm{m}^{2}\right)$ and extreme obesity $\left(\mathrm{BMI} \geq 35 \mathrm{~kg} / \mathrm{m}^{2}\right)$ were most prevalent in the age group 60-70 years.

\section{Disordered eating}

In women $<30$ years old, $11.8 \%$ (95\% CI 10.3 to 13.1 ; $\mathrm{n}=206$ ) reported DE. In the subscale 'oral control', 92 women $(5.2 \%$, 95\% CI 4.2 to 6.3$)$ screened positively and in the subscale 'bulimia and food preoccupation', 194 women $(11.1 \%, 95 \%$ CI 9.6 to 12.6$)$ screened positively. Weight problems were associated with DE overall and with both factors: oral control and bulimia and food preoccupation (shown in table 3). Underweight women had almost five times higher odds of high oral control than normal weight women. Women in the obese category were more likely than the normal weight women to exhibit symptoms of bulimia and food preoccupation (see table 3). DE was not associated with younger age or education in this age range. The mean raw score of the EAT-8 sum was 11.85 (SD 2.8), and the median 12 (range XY). The age-adjusted prevalence of DE is presented in table 2 .
Table 2 Age-adjusted prevalence of DE

\begin{tabular}{|c|c|c|}
\hline DE & Prevalence* & $\begin{array}{l}95 \% \mathrm{Cl} \\
\text { Lower to upper }\end{array}$ \\
\hline \multicolumn{3}{|c|}{ EAT-8, years } \\
\hline $20-24.9$ & 13.4 & 11.2 to 15.7 \\
\hline $25-29.9$ & 9.8 & 7.9 to 11.8 \\
\hline \multicolumn{3}{|c|}{ Oral control, years } \\
\hline $20-24.9$ & 6.2 & 4.8 to 7.9 \\
\hline $25-29.9$ & 4.1 & 2.8 to 5.3 \\
\hline \multicolumn{3}{|c|}{ Bulimia and food preoccupation, years } \\
\hline $20-24.9$ & 12.0 & 10.0 to 14.1 \\
\hline $25-29.9$ & 9.9 & 7.9 to 12.1 \\
\hline \multicolumn{3}{|c|}{ EDS-5, years } \\
\hline $30-39$ & 15.7 & 14.4 to 17.0 \\
\hline $40-49$ & 13.1 & 12.1 to 14.1 \\
\hline $50-59$ & 11.3 & 10.4 to 12.1 \\
\hline $60-69$ & 9.3 & 8.4 to 10.3 \\
\hline$\geq 70$ & 0 & \\
\hline
\end{tabular}

In the age group 30-90 years, 1977 women (12\%, 95\% CI 11.5 to 12.6 ) reported DE. Both in univariate and multivariate models, overweight and obese women had higher odds of DE than did normal weight women. The associations between BMI and DE were stronger in the multivariate analysis for women in the obese and extremely obese categories, (OR $12.095 \%$ CI 10.03 to 14.41) and (OR 22.50 95\% CI 18.37 to 27.55), respectively. Women with a higher level of education were more likely to report DE (OR $1.1495 \%$ CI 1.02 to 1.27 ). DE was associated with younger age.

\section{Dieting and weight dissatisfaction}

Weight dissatisfaction was unrelated to BMI and age in crude and adjusted models, as shown in table 3. Overall, $58.8 \%$ of the women reported weight dissatisfaction. In the underweight group, $62.2 \%$ were dissatisfied with their weight, and $59.7 \%$ believed they were too heavy. Of those satisfied with their weight, $40.8 \%$ were in the obese category and $41.3 \%$ were in the extremely obese category. Women with weight dissatisfaction were seven times more likely to be dieters than non-dieters. More than half $(54.1 \%)$ of 26710 women reported dieting, and $13.5 \%$ reported that they recurrently tried to lose weight. There were no differences in BMI between nondieters and dieters or frequencies of dieting. The likelihood of being on a diet was similar for women of all ages (table 4 ).

\section{DISCUSSION}

In this study, high rates of overweight $(38 \%)$ and obesity (23.1\%) were found, and DE was associated with weight problems. About $12 \%$ of women presented with DE, and a high prevalence of weight dissatisfaction (58.8\%) and 
Table 3 Logistic regression for the effect of weight on DE, oral control, and bulimia and food preoccupation in women $<30$ years of age

\begin{tabular}{llll}
\hline & OR $(\mathbf{9 5 \%} \mathbf{~ C l})$ adjusted & & \\
\cline { 2 - 3 } & DE overall & Oral control & Bulimia and food preoccupation \\
\hline Normal weight & Reference group & Reference group & Reference group \\
Underweight & $3.34(1.72 \text { to } 6.49)^{\star}$ & $4.70(2.25 \text { to } 9.80)^{\star}$ & $1.14(0.44$ to 2.96$)$ \\
Overweight & $0.83(0.57$ to 1.22$)$ & $0.44(0.23$ to 0.84$)$ & $1.23(0.84$ to 1.80$)$ \\
Obese & $0.94(0.52$ to 1.70$)$ & $0.39(0.12$ to 1.26$)$ & $2.22(1.35 \text { to } 3.66)^{\star}$ \\
Extremely obese & $1.73(0.92$ to 3.26$)$ & $1.23(0.48$ to 3.19$)$ & $1.40(0.67$ to 2.91$)$ \\
\hline
\end{tabular}

${ }^{*}$ Adjusted for age, education and smoking. Analysed for complete cases on all variables.

$\mathrm{DE}$, disordered eating.

dieting (54.1\%) was found. Weight dissatisfaction, but not BMI, was associated with dieting.

Studies on the prevalence of DE in the general population are scarce, and rates have been shown to vary between $8.3 \%$ and $26 \%$ in Western countries. ${ }^{5}$ Hence, comparisons between prevalence figures of $\mathrm{DE}$ are difficult.

Rates of DE have been reported to be slightly lower than in our findings. ${ }^{29}$ However, Solmi $e t a l^{30}$ found a prevalence of $10 \%$ of $\mathrm{DE}$ in a general population sample in the UK, consistent with our findings. A higher prevalence of $\mathrm{DE}$ has been found where as many as one-third of the girls in an adolescent sample reported DE behaviour and attitudes. ${ }^{31}$ The difference in prevalence between the latter study and ours could be due to the different age groups of the samples. In this study, DE was associated with weight problems. Among women $<30$ years of age, underweight was associated with DE. This replicates findings from a large study in a general adolescent population. ${ }^{32}$ However, obesity was associated with symptoms of bulimia and food preoccupation with $\mathrm{DE}$ in women $\geq 30$ years of age, concurrent with findings from a large Austrian study, which showed that DE is not only a problem of severely underweight individuals but also probably an even greater problem for overweight individuals and individuals with obesity. ${ }^{6}$ Also, previous findings have shown loss of control and higher rates of eating restraint in higher BMI categories. ${ }^{30-33}$ Hunger and preoccupation with food due to excessive restriction of food may precede binge eating. ${ }^{34}$ Hence, for some women, DE may precede obesity. The association between $\mathrm{DE}$ in higher weight categories may be reflective of more frequent binge eating and purging leading to weight gain, in line with earlier studies that have shown that binge eating is associated with a high BMI. $^{35}{ }^{36}$ Also, it is possible that women engage in restrictive behaviours to achieve weight loss to a higher degree as their BMI increases.

More than $50 \%$ of the women in our study reported dieting, making it a normative practice. Women's dieting behaviours in this study were largely dependent on weight dissatisfaction and not related to their BMI status. This is in agreement with other studies showing that trying to lose weight is associated to a larger degree with weight satisfaction than with actual weight. ${ }^{37} 38$ There was no difference in BMI between dieters and nondieters, consistent with prospective studies that show dieting to be ineffective in preventing weight gain. ${ }^{19} 39$ As we had no data for previous weight, we cannot infer if the dieters' efforts to lose weight were productive. Nevertheless, there is reason to believe that those dieting have been unsuccessful in efforts to lose weight,

Table 4 Multinomial logistic regression predicting dieting and frequency of dieting

\begin{tabular}{|c|c|c|}
\hline & \multicolumn{2}{|l|}{ Dieting frequency* } \\
\hline & $\begin{array}{l}\text { Dieting sometimes } \\
\text { OR }(95 \% \mathrm{Cl})\end{array}$ & $\begin{array}{l}\text { Dieting frequently } \\
\text { OR }(95 \% \mathrm{Cl})\end{array}$ \\
\hline BMI & $1.00(1.00$ to 1.01$)$ & $1.00(1.00$ to 1.01$)$ \\
\hline Age & $1.00(1.00$ to 1.00$)$ & $1.00(1.00$ to 1.01$)$ \\
\hline \multicolumn{3}{|l|}{ Smoking } \\
\hline Non-smokers & $1.18(1.10$ to 1.28$)$ & $0.90(0.81$ to 1.00$)$ \\
\hline Smoking occasionally & 1.39 (1.21 to 1.59$)$ & $1.08(0.89$ to 1.31$)$ \\
\hline \multicolumn{3}{|l|}{ Education } \\
\hline Lower education & $0.79(0.74$ to 0.84$)$ & 0.99 (0.91 to 1.09$)$ \\
\hline \multicolumn{3}{|l|}{ Weight dissatisfaction } \\
\hline Weight satisfaction & $0.17(0.16$ to 0.18$)$ & $0.04(0.04$ to 0.05$)$ \\
\hline
\end{tabular}


as their BMI status did not differ from those not dieting. Underweight women were just as likely to report dieting as women in other BMI categories. Additionally, nearly two-thirds of underweight women believed they were too heavy, which in turn may have led to their DE. It may be that the measures of DE in this study do not capture women in the general population who have fear of weight gain and who diet when underweight, thus underestimating the prevalence of DE. This is of substantial concern due to the increased mortality risk associated with underweight.

Most women (58.8\%) in our study were dissatisfied with their weight, which is in line with earlier large-scale surveys of weight satisfaction. ${ }^{40}{ }^{41}$ This is an important finding as weight dissatisfaction may have bearing on the development of obesity due to the association with binge eating and purging behaviours. ${ }^{42}$ Weight dissatisfaction was unrelated to BMI in our sample, in conflict with a US study, which found that women satisfied with their bodies had a lower BMI. ${ }^{43} \mathrm{~A}$ considerable number of women were dissatisfied with their weight even when their BMI was within the acceptable limits of healthy weight. This may be of concern given the association between weight dissatisfaction and dieting, as well as other DE behaviours; and the prospective association between weight cycling (ie, weight loss and regain) and weight gain. ${ }^{39}$ Obese individuals have been shown to be dissatisfied with their body size $;{ }^{44}$ this is in disagreement with our findings, as approximately $40 \%$ of the obese women in our study were satisfied with their weight. This noteworthy finding should be explored in more detail in future studies. We did not have any direct measures of emotional health, however, we explored 'satisfaction with life' in women who were obese and satisfied with their weight compared to those obese women who were dissatisfied with their weight, and found no differences between the groups. It may also suggest that individuals over time become more tolerant of higher body weight, and are thus less likely to perceive themselves as overweight. ${ }^{45}$ Also, the overall increase in BMI in the general population may have contributed to a normalisation of overweight and obesity.

DE was not associated with younger age in women between the ages of 19-30 years, possibly explained by the narrow age span. As expected, younger age was associated with DE in women aged above 30 years. ${ }^{46}$ However, the effect was weak, suggesting that DE is present in women of all ages. Traditionally, weight satisfaction is related to older age. ${ }^{38}$ However, we found no association between age and weight dissatisfaction, consistent with other research where age was found to be unrelated to body satisfaction. ${ }^{40} \mathrm{DE}$, awareness of body image and the societal pressure of a thin body image may affect women of all ages to a larger degree than previously perceived. However, more pathological indicators of body image disturbance such as overvaluation of weight and shape, or preoccupation of weight/shape may vary across age groups.
Previously, EDs were associated with higher social class, ${ }^{47}$ but recent evidence indicates that neither educational level nor socioeconomic status is likely to influence DE. ${ }^{46-48}$ In this study, education was not associated with DE in the age group 19-30 years. Moreover, across all age groups, women with a lower level of education were more likely to be dissatisfied with their weight than women with a higher education, signifying that $\mathrm{DE}$ and weight dissatisfaction can affect women irrespective of educational attainment. However, in women $\geq 30$ years of age, higher levels of education were associated with DE. The differences in these findings might reflect secular changes, that is, the thin ideal being more pervasive now, thus affecting women regardless of degree of education.

We did not aim to define the majority of obese and underweight women as eating disordered, consequently pathologising a large proportion of women. However, our findings suggest a strong association between weight problems and DE. To the best of our knowledge, this study is the largest of its kind to investigate the prevalence of DE, weight problems, weight dissatisfaction and dieting across weight groups in a large general population sample of women with a wide age span. The strengths of the study are its objective assessment of weight and height. Owing to the cross-sectional nature of the analyses, a limitation is that the temporality of the relationships between variables cannot be established.

Even though numerous tools have been developed to assess eating pathology, evidence for case detection of DE remains limited. ${ }^{49}$ Moreover, estimation and comparison of prevalence of $\mathrm{DE}$ in the general population remains a methodological challenge because different instruments have been used in different studies.

A limitation of this study lies in the use of the shortened version of the EAT and the rarely used EDS-5, which reduces the ability to compare across age groups. As we did not have the opportunity to compare the EAT-8 and the EDS-5 with another test, using a 'gold standard technique' with one group being 'normal' (negative) in this study, we were not able to perform sensitivity analyses using different cut-off points. Hence, comparisons of prevalence rates with other populations must be tentative. We must also consider that the instruments used to assess DE in this study may not necessarily detect the same aspects of DE pathology, which may partly explain why DE was associated with both underweight and obesity.

\section{Conclusions}

A high prevalence of DE along with weight problems was found in this sample. Further, a high rate of weight dissatisfaction and dieting was found in women of all ages, unrelated to BMI. Findings from the present study suggest that weight problems and DE are not distinct from one another. This should inspire clinicians and researchers to develop combined prevention and treatment approaches to these disorders. 
This study also indicates that the public health messages concerning DE and weight problems should perhaps focus more on the importance of weight satisfaction and not simply on actual weight.

\section{Twitter Follow Trine Eik-Nes at @tetnes}

Contributors TE-N conducted all analyses under the supervision of UR, SB and $\mathrm{TH}$; and NM provided direct supervision to TE-N as part of her PhD programme at the Norwegian University of Science and Technology, Norway. All the authors were involved in manuscript writing and final approval of the manuscript.

Funding This work was funded by the Liaison Committee between the Central Norway Regional Health Authority (RHA) and the Norwegian University of Science and Technology (NTNU), Norway.

\section{Competing interests None declared.}

Ethics approval The Regional Committee for Ethics in Medical Research in Central Norway.

Provenance and peer review Not commissioned; externally peer reviewed.

Data sharing statement Data used from the HUNT survey in research projects will, when reasonably requested by others, be made available on request to the HUNT Data Access Committee (hunt@medisin.ntnu.no). The HUNT data access information (available here: http://www.ntnu.edu/hunt/data) describes in detail the policy regarding data availability.

Open Access This is an Open Access article distributed in accordance with the Creative Commons Attribution Non Commercial (CC BY-NC 4.0) license, which permits others to distribute, remix, adapt, build upon this work noncommercially, and license their derivative works on different terms, provided the original work is properly cited and the use is non-commercial. See: http:// creativecommons.org/licenses/by-nc/4.0/

\section{REFERENCES}

1. Flegal KM, Carroll MD, Kit BK, et al. Prevalence of obesity and trends in the distribution of body mass index among us adults, 1999-2010. JAMA 2012;307:491-7.

2. Jones JM, Bennett S, Olmsted MP, et al. Disordered eating attitudes and behaviours in teenaged girls: a school-based study. CMAJ 2001;165:547-52.

3. Austin SB, Ziyadeh NJ, Forman S, et al. Screening high school students for eating disorders: results of a national initiative. Prev Chronic Dis 2008;5:A114.

4. Micali N, Hagberg KW, Petersen I, et al. The incidence of eating disorders in the UK in 2000-2009: findings from the General Practice Research Database. BMJ Open 2013;3:e002646.

5. Makino M, Tsuboi K, Dennerstein L. Prevalence of eating disorders: a comparison of Western and non-Western countries. Med Gen Med 2004;6:49.

6. Zeiler M, Waldherr K, Philipp J, et al. Prevalence of eating disorder risk and associations with health-related quality of life: results from a large school-based population screening. Eur Eat Disord Rev Published online: 26 May 2015. doi:10.1002/erv.2368

7. Hay PJ, Mond J, Buttner P, et al. Eating disorder behaviors are increasing: findings from two sequential community surveys in South Australia. PLOS ONE 2008;3:e1541.

8. Hudson JI, Hiripi E, Pope HG Jr., et al. The prevalence and correlates of eating disorders in the National Comorbidity Survey Replication. Biol Psychiatry 2007;61:348-58.

9. Agras WS. The consequences and costs of the eating disorders Psychiatr Clin North Am 2001;24:371-9.

10. Arcelus $\mathrm{J}$, Mitchell $\mathrm{AJ}$, Wales $\mathrm{J}$, et al. Mortality rates in patients with anorexia nervosa and other eating disorders. A meta-analysis of 36 studies. Arch Gen Psychiatry 2011;68:724-31.

11. Kjelsås E, Bjørnstrøm C, Götestam KG. Prevalence of eating disorders in female and male adolescents (14-15 years). Eat Behav 2004:5:13-25.

12. Wertheim $\mathrm{EH}$. The prevention of eating problems and eating disorders: theory, research and practice. In: Levine MP, Smolak L. Mahwah, Oxford, UK: Lawrence Erlbaum Associates, 2006:86-8.

13. Fairburn CG, Brownell KD. Eating disorders and obesity: a comprehensive handbook. 2nd edn. New York: Guilford Press, 2002.
14. Neumark-Sztainer DR, Wall MM, Haines JI, et al. Shared risk and protective factors for overweight and disordered eating in adolescents. Am J Prev Med 2007;33:359-69.

15. Wardle J, Marsland L. Adolescent concerns about weight and eating; a social-development perspective. J Psychosom Res 1990;34:377-91.

16. Micali N, De Stavola B, Ploubidis G, et al. Eating disorders behaviours and cognitions in adolescence: gender-specific patterns in the prospective effect of child, maternal and family risk factors. Br J Psychiatry 2015;207:320-7.

17. Field AE, Austin SB, Taylor CB, et al. Relation between dieting and weight change among preadolescents and adolescents. Pediatrics 2003;112:900-6.

18. Patton GC, Johnson-Sabine E, Wood K, et al. Abnormal eating attitudes in London schoolgirls-a prospective epidemiological study: outcome at twelve month follow-up. Psychol Med 1990;20:383-94.

19. French SA, Jeffery RW, Forster JL, et al. Predictors of weight change over two years among a population of working adults: the Healthy Worker Project. Int J Obes Relat Metab Disord 1994;18:145-54.

20. Haines J, Neumark-Sztainer D. Prevention of obesity and eating disorders: a consideration of shared risk factors. Health Educ Res 2006;21:770-82.

21. Krokstad S, Langhammer A, Hveem K, et al. Cohort profile: the HUNT Study, Norway. Int J Epidemiol 2013;42:968-77.

22. Garner DM, Garfinkel PE. The Eating Attitudes Test: an index of the symptoms of anorexia nervosa. Psychol Med 1979;9:273-9.

23. Lavik NJ, Clausen SE, Pedersen W. Eating behaviour, drug use, psychopathology and parental bonding in adolescents in Norway. Acta Psychiatr Scand 1991;84:387-90.

24. Bjomelv S, Mykletun A, Dahl AA. The influence of definitions on the prevalence of eating problems in an adolescent population. Eat Weight Disord 2002;7:284-92.

25. Holmen TL, Bratberg G, Krokstad S, et al. Cohort profile of the Young-HUNT Study, Norway: a population-based study of adolescents. Int J Epidemiol 2014;43:536-44.

26. Rosenvinge JH, Perry JA, Bjørgum L, et al. A new instrument measuring disturbed eating patterns in community populations: development and initial validation of a five-item scale (EDS-5). Eur Eat Disord Rev 2001;9:123-32.

27. Garner DM. EDI-2. Eating Disorder inventory-2. Professional manual. Odessa, FL: Psychological Assessment Resources, 1991.

28. Midthjell K, Lee CM, Langhammer A, et al. Trends in overweight and obesity over 22 years in a large adult population: the HUNT Study, Norway. Clin Obes 2013;3:12-20.

29. McBride O, McManus S, Thompson J, et al. Profiling disordered eating patterns and body mass index (BMI) in the English general population. Soc Psychiatry Psychiatr Epidemiol 2013;48:783-93.

30. Solmi F, Hatch SL, Hotopf $M$, et al. Prevalence and correlates of disordered eating in a general population sample: the South East London Community Health (SELCoH) study. Soc Psychiatry Psychiatr Epidemiol 2014:49:1335-46.

31. Herpertz-Dahlmann B, Wille $\mathrm{N}$, Holling $\mathrm{H}$, et al. Disordered eating behaviour and attitudes, associated psychopathology and health-related quality of life: results of the BELLA study. Eur Child Adolesc Psychiatry 2008;17(Suppl 1):82-91.

32. Bjornelv S, Nordahl HM, Holmen TL. Psychological factors and weight problems in adolescents. The role of eating problems, emotional problems, and personality traits: the Young-HUNT study. Soc Psychiatry Psychiatr Epidemiol 2011;46:353-62.

33. de Zwaan M. Binge eating disorder and obesity. Int J Obes Relat Metab Disord 2001;25(Suppl 1):S51-5.

34. McManus F, Waller G. A functional analysis of binge-eating Clin Psychol Rev 1995;15:845-63.

35. Marcus MD, Bromberger JT, Wei HL, et al. Prevalence and selected correlates of eating disorder symptoms among a multiethnic community sample of midlife women. Ann Behav Med 2007;33:269-77.

36. Marcus MD, Kalarchian MA. Binge eating in children and adolescents. Int J Eat Disord 2003;34(S1):S47-57.

37. Mikkila V, Lahti-Koski M, Pietinen $\mathrm{P}$, et al. Associates of obesity and weight dissatisfaction among Finnish adolescents. Public Health Nutr 2003:6:49-56.

38. Anderson LA, Eyler AA, Galuska DA, et al. Relationship of satisfaction with body size and trying to lose weight in a national survey of overweight and obese women aged 40 and older, United States. Prev Med 2002;35:390-6.

39. Field AE, Byers T, Hunter DJ, et al. Weight cycling, weight gain, and risk of hypertension in women. Am J Epidemiol 1999;150: 573-9. 
40. Frederick DA, Peplau LA, Lever J. The swimsuit issue: correlates of body image in a sample of 52,677 heterosexual adults. Body Image 2006;3:413-19.

41. Matthiasdottir E, Jonsson SH, Kristjansson AL. Body weight dissatisfaction in the Icelandic adult population: a normative discontent? Eur J Public Health 2012;22:116-21.

42. Agliata D, Tantleff-Dunn S. The impact of media exposure on males' body image. J Soc Clin Psychol 2004;23:7-22.

43. Runfola CD, Von Holle A, Peat CM, et al. Characteristics of women with body size satisfaction at midlife: results of the Gender and Body Image (GABI) Study. J Women Aging 2013;25:287-304.

44. Wardle J. Is Obesity an eating disorder? Eur Health Psychol 2009;11:52-5.

45. Johnson-Taylor WL, Fisher RA, Hubbard VS, et al. The change in weight perception of weight status among the overweight: comparison of NHANES III (1988-1994) and 1999-2004 NHANES. Int J Behav Nutr Phys Act 2008;5:9.

46. Mitchison D, Hay PJ. The epidemiology of eating disorders: genetic, environmental, and societal factors. Clin Epidemiol 2014;6:89-97.

47. Gibbons P. The relationship between eating disorders and socioeconomic status: it's not what you think. Nutr Noteworthy 2001;4. http://escholarship.org/uc/item/1k70k3fd

48. Favaro A, Ferrara S, Santonastaso P. The spectrum of eating disorders in young women: a prevalence study in a general population sample. Psychosom Med 2003; 65:701-8.

49. Jacobi C, Abascal L, Taylor CB. Screening for eating disorders and high-risk behavior: caution. Int J Eat Disord 2004;36: 280-95. 